\title{
LXXIX. On some extraordinary inconsistencies in the Greenwich observations for 1821
}

\section{S. Lee Esq.}

To cite this article: S. Lee Esq. (1824) LXXIX. On some extraordinary inconsistencies in the Greenwich observations for 1821, Philosophical Magazine Series 1, 64:320, 451-455, DOI: $10.1080 / 14786442408644638$

To link to this article: http://dx.doi.org/10.1080/14786442408644638

册 Published online: 27 Jul 2009.

Submit your article to this journal

Џ Article views: 2

Q View related articles $\square$ 
LXXIX. On some Extraordinary Inconsistencies in the Greenwich Observations for 1821. By S. LEe, Esq.

To the Editors of the Philosophical Magazine and Journal.

Gentlemen,

IN my letter of the 24th November last, I pointed out some extraordinary inconsistencies in the Greenwich .observations for 1821. I now proceed to notice some others of a different description, and which for the reasons already given, I have arranged in three separate additional classes.

Class IV. exhibits a comparative view of the intervals of time between the meridian passages of certain stars, as observed on the same night, with the transit instrument and the mural circle.

Class V. contains the north polar distances of $\gamma$ Draconis, and some other remarkable stars, taken out of the observations with the mural circle, from readings with two and with six microscopes.

Class VI. gives the intervals of time between the passage of some of the principal fixed stars, by the wires of the transit instrument, as observed on different nights.

With respect to the three first classes, little more can be said than that they prove extreme carelessness in the observer, the transcriber, or the computer; for, as I have already stated, they are not the faults of the printer.

The fourth class show that proper care has not been taken to bring the plane of the mural circle truly into the plane of the meridian. It may be alleged, that a small deviation therefrom does not, in most cases, occasion any considerable error in the north polar distances: but it must also be admitted, that such want of adjustment, however insignificant its effect, ought not to be allowed to remain in one of the principal instruments of the Royal Observatory at Greenwich.

It is very remarkable that so few transits should have been taken with the Circle, and that the stars observed should be so ill adapted to the purpose of ascertaining the correctness of its position. - Indeed, it is hardly possible to imagine a more injudicious selection.

The observations which form the fifth class were extracted for the purpose of ascertaining the stability of the Circle.

$A$ very slight comparison of these extracts with one another, will convince any one (supposing the observations to have been carefully made and accurately recorded) that the instrument must be extremely unsteady.

Such extravagant variations of north polar distance from

$3 \mathrm{~L} 2$ 
one night to another, frequently in direct opposition to what might have been expected from refraction, aberration, or nutation, and so capricious as to defy even a southern motion to explain-ought to have attracted the attention of the observer, and instantly led to a suspicion of something wrong: but full eight months were suffered to elapse before any notice was taken of them. Such a lamentable ignorance of the state of the instrument could never have existed for a single day, had the Circle been provided with a plumb-line or a level, or had the zenith sector been employed in conjunction with it, for ascertaining its line of collimation.

The sixth class consists of observations of the passage of certain remarkable fixed stars, by the wires of the justly celebrated ten-feet transit instrument, and are intended to show the degree of confidence due to an observation by any single wire. A comparison of the observations of the same star on different nights, plainly shows that the Greenwich transits are liable to errors which one would hardly expect to find in observations with an instrument of only as many inches focal length.

The observations of transits with the mural circle appear to be noted down with a very culpable degree of negligence: as a proof of which, it is only necessary to cite a few examples from the Observations of 1822 just published.-On \& $3 \mathrm{~d}$ of June, Castor passed the meridian instead of Procyon. On 2 20th of July, Arcturus is made to pass the meridian twice in the space of little more than two hours. On $\odot 28$ th of July, $\alpha$ Ophiuchi passed the meridian of the Circle-room about $1^{\mathrm{h}} 1^{\mathrm{m}}$ before it passed the meridian of the Transit-room; and $\delta$ 30th of July, in the Transit-room a Corona passed the meridian $8^{\mathrm{m}} 21^{\mathrm{s}}$ before a Serpentis, but in the Circle-room not till $\mathrm{I}^{\mathrm{m}} 38^{\mathrm{s}}$ after that star.

The intervals between the transits of $\alpha$ Lyra and $\alpha^{2} \mathrm{Ca}$ pricorni in the Circle observations for the same year, frequently differ more than $2^{\prime \prime}$ from the true interval; which (if these observations are to be relied on) show that in 1822 that instrument was still more out of the meridian than in 1821 .

During the whole of the year 1821, only sixteen eclipses of Jupiter's satellites were observed at Greenwich; though no less than eighteen were observed in the last five months alone by Mr. Beaufoy at Bushy. No occultations of the stars by the moon are to be found. The occultation of the Pleiades by the moon on the 13th of October is not noticed, though observed at Bushy; and the weather seems to have been favourable, for the transit of a Pegasi, which took place on that night about a quarter of an hour before the occultation, was observed at Greenwich. 
The comet also which was observed by Dr. Burney at Gosport, on the evening of the 24th of February, and on several evenings after, appears to have been overlooked.

It seems to be the practice at Greenwich (for six nights in a week at least) to cease observing from midnight to sun-rise. For it would be difficult to prove from the observations of 1821, that either the astronomer or any of his assistants quitted their warm beds much more than about 40 nights out of 365 , for the purpose of making an observation.

There is no institution in the world so amply endowed in every respect as the Royal Observatory at Greenwich. It was a favourite object with the late king; and the truly royal munificence of its present patron must be acknowledged with gratitude by every sincere friend to astronomy. Provided with no less than four assistants, whose salaries, added to his own, amount to upwards of $1200 l$. a-year,-surely the Astronomer Royal might appropriate a rather larger portion of the night to the cultivation of the science over which he is appointed to preside, with so many advantages and encouragements. Instruments and books have been furnished here in abundance, without the least regard to expense, and every accommodation that private comfort can require, granted without reserve. London, Dec. 20, 1824. I am, gentlemen, yours, \&c.

Stephen Lee.

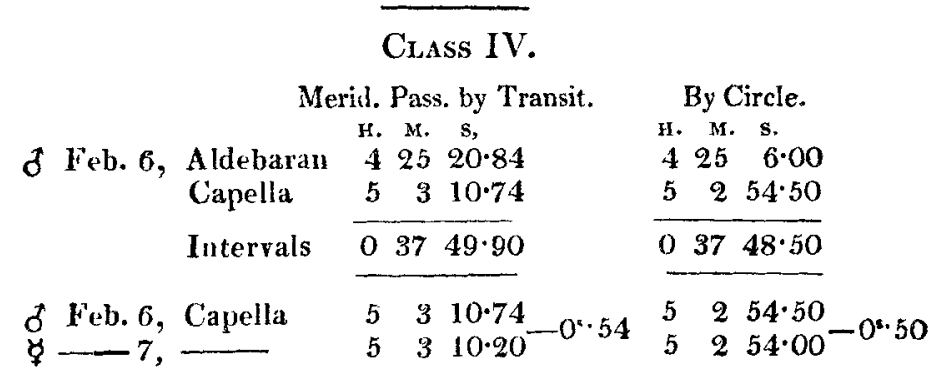

Therefore the rates of the two clocks were so nearly alike that no allowance need be made on that account. But the interval between the passage of Aldebaran and Capella is $1^{\text {s.4. }}$ of time greater by the transit than by the circle.

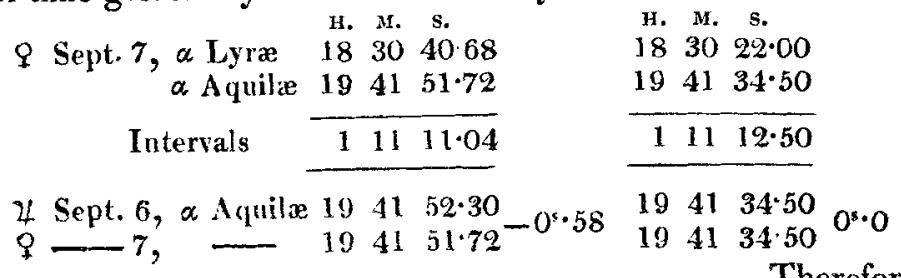

Therefore 
164 Mr. Lee on some Lixtraordinary Inconsistencies

Therefore allowing $0^{s .03}$ for the different rates of the clocks, the interval between the passage of $\alpha$ Lyrce and $\alpha$ Aquile is 15.43 of time less by the transit than-by the circle.

\section{Class V.}

1. N.P.D. of Polaris above the Pole.

With 2 Microscopes. With 6 Microscopes.

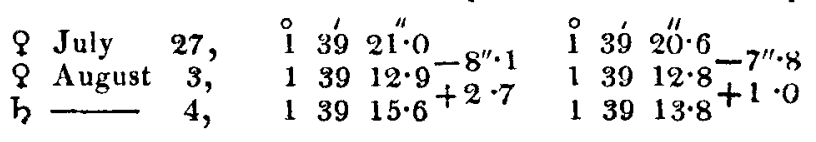

2. N.P.D. of Polaris below the Pole.

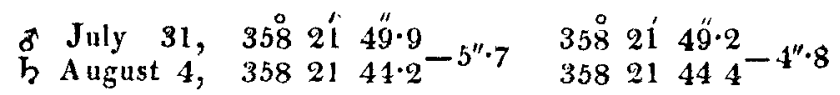

3. N.P.D. of Capella.

July 28,
August 3, 4 i 11́ $30 \cdot 5$ $411124 \cdot 9^{-5} 6$ $\begin{array}{llll}44 & 11 & 28 \cdot 4 \\ 44 & 11 & 22 \cdot 9^{-3} \cdot 5\end{array}$

4. N.P.D. of $\beta$ Tauri.

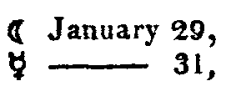
6 î $3 \dot{2} 33 \cdot 1$
$\begin{array}{llll}6 i & 32 & 31 \cdot 7 & \\ \text { C1 } & 32 & 31 \cdot 7 & 0^{\prime \prime} \cdot 0\end{array}$

5. N.P.D. $\gamma$ Draconis.

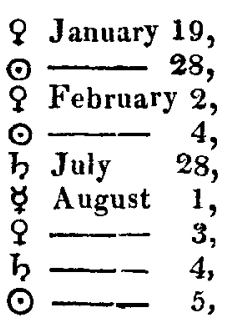

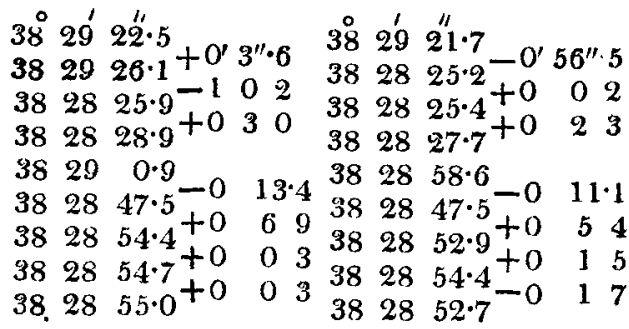

6. N.P.D. a Lyre.

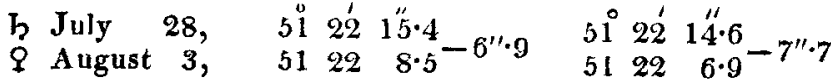

7. N.P.D. a Cygni.

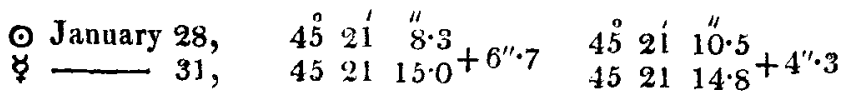


Ciass VI.

Passage by the Wires of the Transit Instrument.

1. Aldebaran.

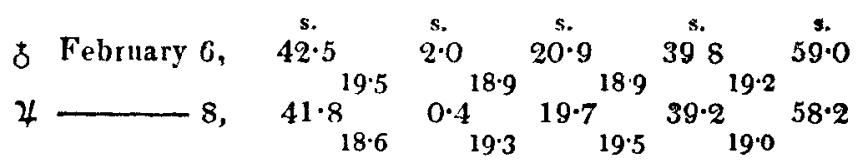

2. Capella.

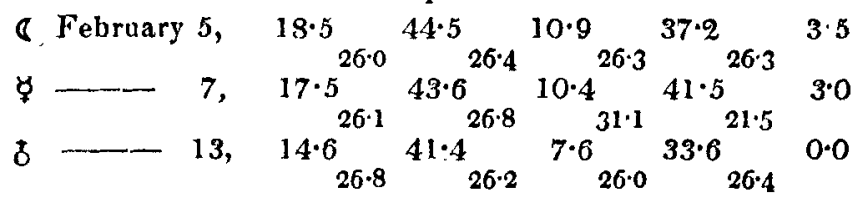

3. Sirius.

4) February 8, $18 \cdot 2{ }_{19.1}^{37 \cdot 3}{ }_{19.2}^{56.5} 19.015 .5 \quad 14.5$ 8 $19, \quad 14 \cdot 6{ }_{19 \cdot 5}^{34 \cdot 1}{ }_{19 \cdot 1}^{53 \cdot 2}{ }_{19 \cdot 1}^{12 \cdot 3}{ }_{18 \cdot 9}^{31 \cdot 2}$

4. Castor.

ఫ March 14, 51.1 12.5 34.5 $35.7 \quad 17.5$ $\odot$ April $8, \quad 55 \cdot 5{ }_{22.3}^{17 \cdot 8}{ }_{21 \cdot 2}^{39 \cdot 0}{ }_{21 \cdot 6} 0 \cdot 6{ }_{21 \cdot 5}^{22 \cdot 1}$

5. Procyon.

4 February 15, $57 \cdot{ }_{18 \cdot 3}^{16 \cdot 0}{ }_{18 \cdot 3}^{34 \cdot 3}{ }_{18 \cdot 3}^{52 \cdot 6}{ }_{17.7}^{10 \cdot 3}$ $8-19,56.6{ }_{18.6} 15.2{ }_{18.3}^{33.5}{ }_{18.3} 51.8{ }_{18.6} 10.4$

9 March 16, 41.3 ${ }_{19.0}^{0.3}{ }_{18.0}^{18.3}{ }_{18.9}^{37.2}{ }_{18.2}^{55.4}$ $9-30, \quad 29 \cdot 0{ }_{19 \cdot 6}^{48 \cdot 6}{ }_{19.9}^{8.5}{ }_{18.8}^{27 \cdot 3}{ }_{18.4}^{43.7}$

6. a Aquarii.

q October 31, $59 \cdot 2{ }_{18 \cdot 6}^{17 \cdot 8}{ }_{18 \cdot 5}^{36 \cdot 3}{ }_{23 \cdot 3}^{59 \cdot 6}{ }_{13 \cdot 6}^{13 \cdot 2}$ o November 6, 58.5 ${ }_{18.0}^{16 \cdot 5}{ }_{18.7}^{35 \cdot 2}{ }_{18 \cdot 3}^{53.5}{ }_{18.4}^{11 \cdot 9}$ $9-23, \quad 54 \cdot 2{ }_{18.6}^{12 \cdot 8}{ }_{18 \cdot 1}^{30 \cdot 9}{ }_{18 \cdot 4}^{49 \cdot 3}{ }_{18 \cdot 4} 7 \cdot 7$ 